\title{
Tailoring Extra-Strength of a TWIP Steel by Combination of Multi-Pass Equal-Channel Angular Pressing and Warm Rolling
}

\author{
Marina Abramova ${ }^{1}{ }^{\mathbb{D}}$, Arseniy Raab ${ }^{1}$, Ruslan Z. Valiev ${ }^{1,2}$, Anna Khannanova ${ }^{1}$, Chong Soo Lee ${ }^{3} \mathbb{D}$, \\ Jae Nam Kim ${ }^{3}{ }^{D}$, Gyeong Hyeon Jang ${ }^{3} \mathbb{D}$, Jung Gi Kim ${ }^{4}$, Hyoung Seop Kim ${ }^{5} \mathbb{D}$, Oliver Renk ${ }^{6}$ \\ and Nariman Enikeev $1,2, * \mathbb{D}$
}

check for updates

Citation: Abramova, M.; Raab, A.; Valiev, R.Z.; Khannanova, A.; Lee, C.S.; Kim, J.N.; Jang, G.H.; Kim, J.G.; Kim, H.S.; Renk, O.; et al. Tailoring Extra-Strength of a TWIP Steel by Combination of Multi-Pass Equal-Channel Angular Pressing and Warm Rolling. Metals 2021, 11, 518. https://doi.org/10.3390/ met11030518

Academic Editor: Jin-Kyung Kim

Received: 26 February 2021

Accepted: 16 March 2021

Published: 22 March 2021

Publisher's Note: MDPI stays neutral with regard to jurisdictional claims in published maps and institutional affiliations.

Copyright: (c) 2021 by the authors. Licensee MDPI, Basel, Switzerland. This article is an open access article distributed under the terms and conditions of the Creative Commons Attribution (CC BY) license (https:/ / creativecommons.org/licenses/by/ $4.0 /)$.
1 Institute for Physics of Advanced Materials, Ufa State Aviation Technical University, K. Marx 12, 450008 Ufa, Russia; abramovamm@yandex.ru (M.A.); agraab@mail.ru (A.R.); ruslan.valiev@ugatu.su (R.Z.V.); anya.belkina0021@mail.ru (A.K.)

2 Laboratory of Mechanics of Advanced Bulk Nanomaterials for Innovative Engineering Applications, Saint Petersburg State University, 199034 St. Petersburg, Russia

3 Graduate Institute of Ferrous Technology, Pohang University of Science and Technology, Pohang 37673, Korea; cslee@postech.ac.kr (C.S.L.); jnkims@postech.ac.kr (J.N.K.); ghjang94@postech.ac.kr (G.H.J.)

4 Department of Materials Engineering and Convergence Technology (Center for K-Metals), Gyeongsang National University, Jinju 52828, Korea; junggi91@gnu.ac.kr

5 Department of Materials Science and Engineering, Pohang University of Science and Technology, Pohang 37673, Korea; hskim@postech.ac.kr

6 Erich Schmid Institute of Materials Science, Austrian Academy of Sciences, 8700 Leoben, Austria; Oliver.Renk@oeaw.ac.at

* Correspondence: nariman.enikeev@ugatu.su; Tel.: +7-(3472)-734-449

\begin{abstract}
Increasing the yield stress of twinning-induced plasticity (TWIP) steels is a demanding task for modern materials science. This aim can be achieved by microstructure refinement induced by heavy straining. We feature the microstructural evolution and mechanical performance of a high-manganese TWIP steel subjected to deformation treatment by different combinations of equal channel angular pressing (ECAP) and rolling at different temperatures. The effect of microstructure on the tensile properties of the steel subjected to the multi-pass ECAP process and to subsequent rolling is reported as well. We show that the combined deformation procedure allows us to further increase the strength of the processed workpieces due to a gradual transition from a banded structure to a heterogeneous hierarchical microstructure consisting of fragments, dislocation configurations and nano- and micro-twins colonies. Rolling of multi-pass ECAP specimens at $375{ }^{\circ} \mathrm{C}$ allowed us to achieve an extraordinary strength, the highest among all the investigated cases, while the best trade-off between yield strength and elongation to failure was reached using multi-pass ECAP followed by rolling at $500{ }^{\circ} \mathrm{C}$. This study shows a great potential of using combined deformation techniques to enhance the mechanical performance of TWIP steels.
\end{abstract}

Keywords: TWIP steel; equal-channel angular pressing; rolling; ultrafine-grained materials; microstructure; mechanical properties

\section{Introduction}

The effect of twinning-induced plasticity (TWIP) observed in medium stacking fault energy high-Mn (15-30 wt.\%) austenitic steels is highly attractive for the development of novel tough materials due to their high ability for strain hardening [1,2], presenting a class of second generation advanced high-strength steels. However, the yield stress of these steels in the coarse-grained state is relatively low, which substantially limits their profits for advanced applications [2]. Increasing the yield stress of this steel is quite topical when it relates to lightweight applications related to hydrogen or liquid nitrogen storage. This motivated researchers to use microstructural modification, such as grain refinement, to make these steels stronger [3]. Here, it is important to reveal fundamental peculiarities 
of deformation behavior of high-Mn steels and to find out the limits for their hardening achievable by metal forming techniques.

Severe plastic deformation (SPD) techniques, based on the application of very large shear strains under high pressure, represent a promising tool to substantially refine the microstructure of metallic materials beyond the limits of conventional metal forming processes [4]. Indeed, early attempts to apply high-pressure torsion (HPT), the most powerful SPD technique for microstructure refinement of TWIP steels [5,6] showed an extraordinary increase in microhardness up to levels of $600 \mathrm{HV}$. Moreover, the activation of multiple strengthening mechanisms by processing-controlled formation of fine microstructural features (ultrafine grains and nanoscale twins, grain boundary segregation of $C$, decoration of dislocations by $\mathrm{C}$ and $\mathrm{Mn}$, etc.) allowed achieving an unprecedented tensile strength as high as 2.6 GPa [7].

However, HPT processing generally allows only for rather miniature specimens (typically in the form of discs 10-20 mm in diameter and about $1 \mathrm{~mm}$ thick), which significantly reduces the possibilities of comprehensive macroscopic property characterization and also limits the prospects of potential industrial applications. Equal-channel angular pressing (ECAP), another SPD technique, is capable of producing bulk nanostructured workpieces of much larger size [8] and is thus more attractive for practical use. The first studies of TWIP steels subjected to ECAP $[9,10]$ showed that the resulting microstructures are significantly modified already after one ECAP pass [9]. A study on a TWIP steel subjected to multi-pass ECAP with different processing parameters testified that SPD leads to the formation of a complicated microstructure, consisting of mixed substructures (deformation microbands, dislocation tangles and cells, nano- and microtwins, fragments and subgrains, stacking faults, and so on) [10]. The authors of [10] also observed nucleation of nanotwins inside microtwins/microbands, pointing out an approach to build up a new structural design to modify properties of steels with a TWIP effect. However, ECAP was not effective in producing homogeneous ultrafine-grained structures consisting of a high fraction of high-angle grain boundaries in TWIP steels, such as the case for HPT processing. Nevertheless, by adjusting ECAP processing parameters such as the ECAP route, the number of passes, and the temperature, it was possible to achieve a high-strength state (yield stress of $1480 \mathrm{MPa}$ and ultimate tensile stress of $1624 \mathrm{MPa}$ ) in the alloyed Fe-0.61C-22.3Mn-0.19Si-0.14Ni-0.27Cr TWIP steel [10].

After presenting the above-mentioned first studies, this topic attracted intensive attention of researchers; however, the number of related publications is still limited. So far, the accumulated strains applied do typically not exceed four ECAP passes because TWIP steels proved to be rather difficult to be processed by ECAP, and the workpiece can undergo fracture even after a single ECAP pass, depending on the processing parameters [9]. Further microstructural and mechanical studies of the ECAP-processed TWIP steel assisted with texture analysis showed that the output microstructures are defined by the concurring processes of fragmentation by dislocation slip and by twinning [11]. The critical temperature to switch the dominant deformation mode to dislocation slip was found to be about $300{ }^{\circ} \mathrm{C}$ [11]; however, other authors report on the significant twinning activity even after ECAP at $400{ }^{\circ} \mathrm{C}$ [10]. Despite numerous attempts to additionally impact the strength of TWIP steels by ECAP, the highest yield stress value is still reported to be $1480 \mathrm{MPa}$ [10] accompanied by an ultimate tensile strength of $1675 \mathrm{MPa}[10,11]$, as follows from the most recent review published in [12]. Note that the chemical composition of high-Mn TWIP steels can notably vary; therefore, when comparing the absolute values of the mechanical properties reported in literature, the alloying element content also needs to be considered.

The presented paper is intended to outline the influence of ECAP and a combined $\mathrm{ECAP}+$ rolling deformation treatment on the microstructure and tensile properties of a TWIP steel. 


\section{Materials and Methods}

A TWIP steel with high Mn content provided by the POSCO company (Pohang, Korea, http: / / posco.co.kr, accessed on 19 March 2021) was chosen as an object of investigation. The chemical composition of the steel according to the provided certificate and confirmed by the spectral analysis was Fe-17Mn-2Al-0.6C (wt.\%). The as-received steel was ensured to have a fully recrystallized single-phase austenitic structure facilitating ECAP processing. After etching, the grains were visible by the naked eye, and the average grain size was about $1 \mathrm{~mm}$.

ECAP processing represents a repetitive process of pressing the billet through the die-set which consists of the channels with the same diameter intersected at a certain angle. The geometry of the process realized simple shear in the narrow zone corresponding to the intersection of channels. This scheme allows accumulating high imposed strains into bulk workpieces of different metallic materials. The principles of ECAP and its effect on the microstructure refinement and enhancement of multifunctional properties of different metals and alloys reported in numerous papers are comprehensively overviewed in [13]. Sixty-millimeter-long rods of $10 \mathrm{~mm}$ in diameter were processed by ECAP with an intersection angle of $120^{\circ}$ at $400^{\circ} \mathrm{C}$ by route $\mathrm{Bc}$ (the workpiece was rotated by $90^{\circ}$ between the passes) with the number of passes increasing from $n=1$ to fracture which happened after $n=11$. Such a high number of passes was achieved by a deliberately tuned processing procedure, including not only a rotation of the workpiece by $90^{\circ}$ between the passes, but also by rotating it by $180^{\circ}$ along the axis corresponding to a sample's center in the normal direction after each Bc pass. In addition, the recrystallized state and the ECAP processed material $(n=11)$ were subjected to flat rolling to a reduction ratio of $47 \%$ at $375{ }^{\circ} \mathrm{C}$ and $500{ }^{\circ} \mathrm{C}$ (below and above the ECAP processing temperature).

The samples for SEM/TEM studies were prepared with the help of $20 \% \mathrm{HNO} 3$ solution in butanol by electropolishing at $45 \mathrm{~V}$. JEOL JSM-6490VL and JEOL JEM-2100 microscopes (JEOL Ltd., Tokyo, Japan) were used for these studies, respectively. Assuming considerable heterogeneity of the ECAP-processed steel, we put special attention to TEM characterization, and about 30-50 TEM images were taken per state to identify the most representative structures, which finally were included in the manuscript. Hardness was measured with the Micromet-5101 device (Buehler Ltd., Lake Bluff, IL, USA) with a load of $100 \mathrm{~g}$ for $10 \mathrm{~s}$. After initial evaluation, the hardness was found to be homogeneously distributed across the sample's surface; it was then measured in the normal plane of the rolled samples. Tensile tests were carried out using an INSTRON 8801 testing machine (ToolWorks Inc., Norwood, MA, USA) at room temperature and a nominal strain rate of $5 \times 10^{-4} \mathrm{~s}^{-1}$. Standard round tensile samples with a gauge length of $15 \mathrm{~mm}$ and diameter of $3 \mathrm{~mm}$ were used in case of the ECAP processed material in order to obtain relevant data on the evolution of plasticity with applied strain making use of the bulk dimensions of the ECAP workpiece. The tensile tests of the material processed by rolling were done using flat dog-bone specimens with a gauge with dimensions of $4 \mathrm{~mm} \times 1 \mathrm{~mm} \times 1 \mathrm{~mm}$. It should thus be mentioned that the elongation to failure between the ECAP and ECAP + rolled specimens cannot be directly compared. The tensile samples of the ECAP processed steels were oriented along the pressing direction, and the samples of the rolled samples were cut from the produced sheets so that the gauge was aligned with the rolling direction.

\section{Results}

In the following section, we present the results featuring (i) the progressive evolution of the microstructure of the TWIP steel with increasing the number of ECAP passes and (ii) the influence of ECAP + rolling on the microstructural evolution compared to the conventional rolling treatment only.

\subsection{Evolution of Microstructure and Mechanical Properties of the TWIP Steel Processed by ECAP}

To the best of our knowledge, we present the first report on the TWIP steel subjected to ECAP up to a total accumulated shear strain of about 10, while in the other metallic systems, 
ECAP treatments to higher strains were often reported [13]. Thus, it was important to study the microstructural evolution during deformation. TEM images presented in Figures 1-4 illustrate the progressive changes of the microstructure of the TWIP steel subjected to ECAP.

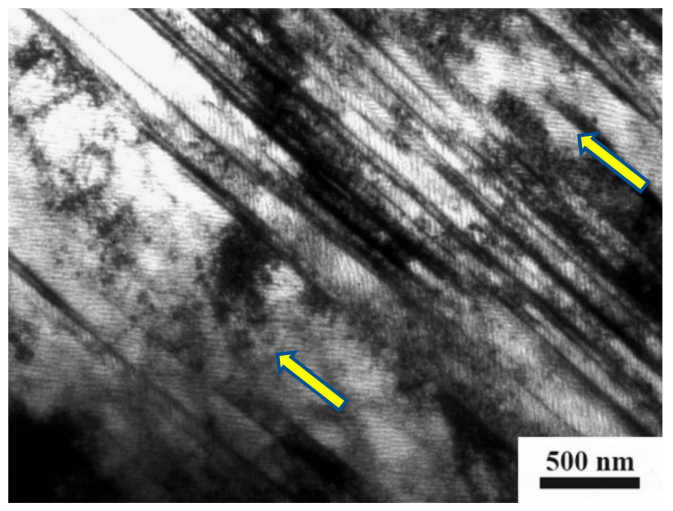

(a)

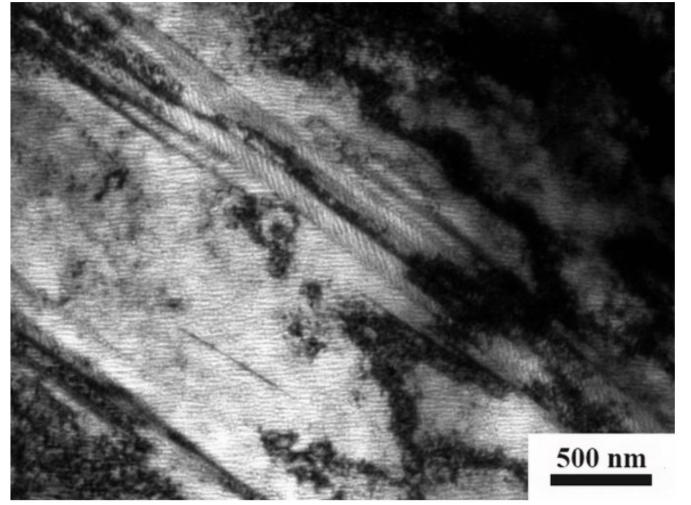

(b)

Figure 1. TEM images (bright field) of the TWIP steel subjected to a single ECAP pass. Regions with fine-scaled twins (a) and wide deformation bands annotated by arrows (b) are shown.

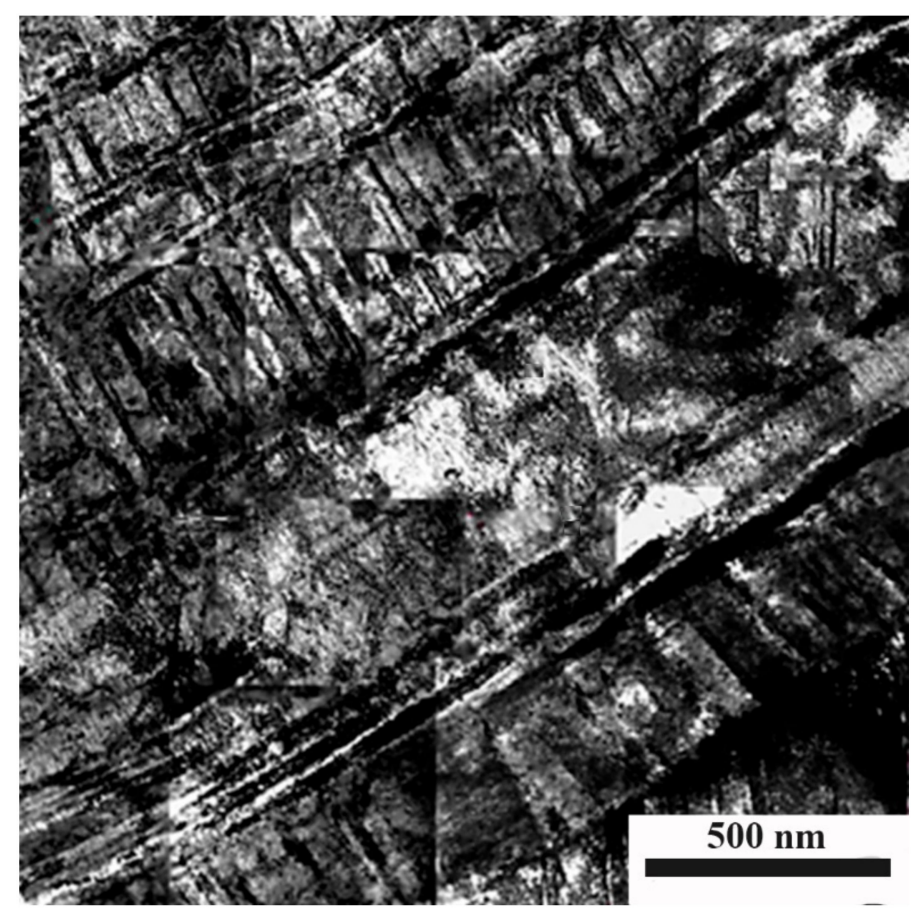

Figure 2. A panoramic TEM image (bright field) of the TWIP steel after two ECAP passes. The image is composed of about 15 standard TEM images stuck together. 


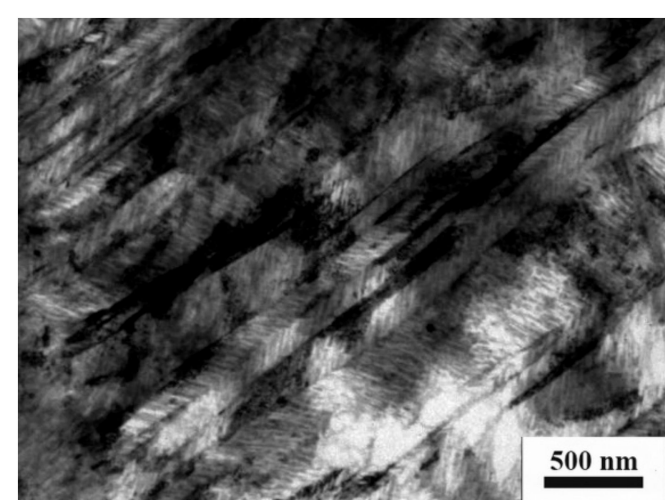

(a)

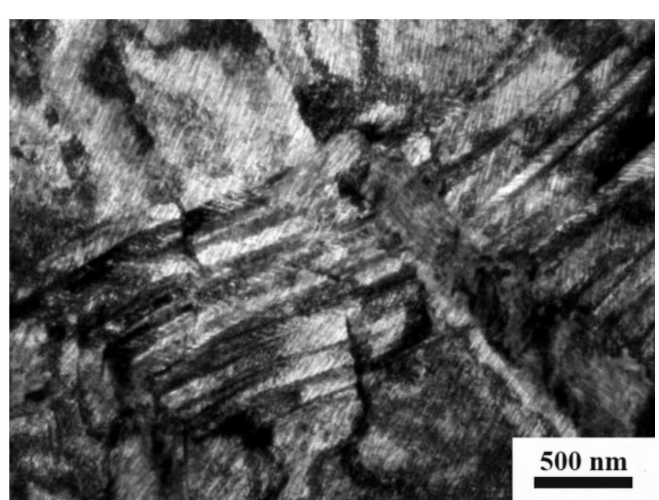

(b)

Figure 3. TEM observations of the fine microstructure of the TWIP steel subjected to 4 ECAP passes. Areas with refined extended deformation bands inhabited with nanotwins (a) and fragmentation of deformation bands (b) are shown.

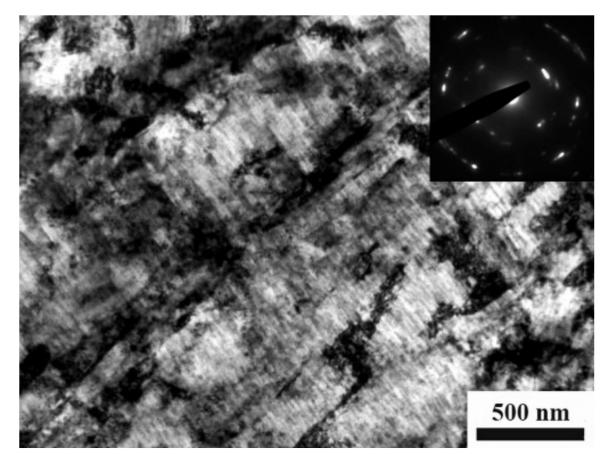

(a)

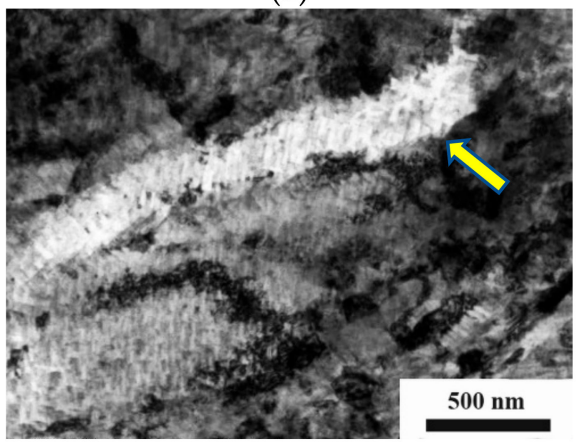

(c)

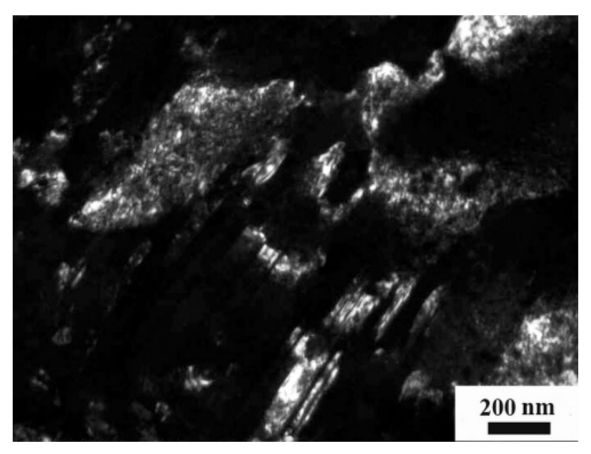

(b)

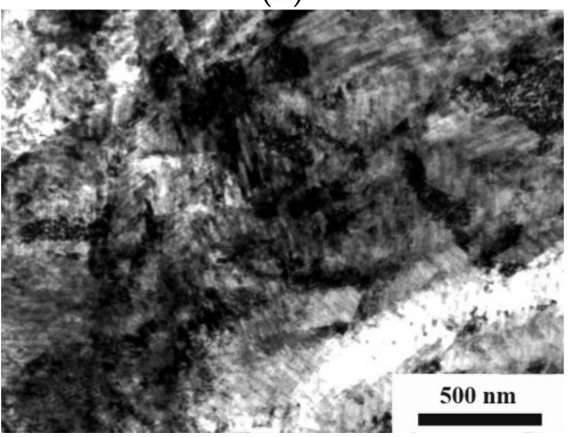

(d)

Figure 4. TEM observations of the fine microstructure of the TWIP steel subjected to ECAP for 11 passes. Bright-field (a) and dark-field (b) images showing the transformation of deformation bands into elongated subgrain structures and a corresponding diffraction pattern (a). Areas with truncated deformation bands annotated by an arrow (c) and newly formed more equiaxed fragments containing high densities of nanotwins are also shown (d). The selected area electron diffraction pattern in (a) was taken from the $1 \mu \mathrm{m}^{2}$ area corresponding to the middle of the image.

After the first ECAP pass, the microstructure (Figure 1) is notably heterogeneous and is characterized by numerous deformation bands (annotated by arrows in Figure 1a) inhibited by dislocation substructures and adjacent twins with spacings of a few tens of nanometers.

Figure 2 represents a panoramic picture composed of several individual TEM images of the TWIP steel subjected to the second ECAP pass. A broader view was required to illustrate the increased heterogeneity of the formed microstructures. The image presented 
in Figure 2 shows deformation bands with a thickness of about $500 \mathrm{~nm}$, with intensive intrinsic twin arrays formed normal to the elongation direction in many of them.

Figure 3 summarizes TEM observations of the microstructure of the TWIP steel subjected to four ECAP passes. It is also composed of deformation bands inhabited with fine nanotwins. The deformation band width notably decreased down to about $35-45 \mathrm{~nm}$. Progressive refinement of the microstructure was also realized by intersection of different families of these deformation bands forming misaligned and disoriented structures.

Further deformation by ECAP to 11 passes (Figure 4) leads to additional qualitative changes of the microstructure, expressed as transformation of the deformation bands into subgrains.

Figure 4 shows the heterogeneous structure after 11 ECAP passes, composed of straininduced highly defective grains/fragments instead of deformation bands, many of which are subdivided by very fine nanoscaled twins. Spots of the electron diffraction pattern (Figure $4 \mathrm{c}$ ) indicate that there is a certain deviation in orientations of the observed grains. There is also a clear trend towards more equiaxed grains in some areas of the deformed material (Figure 4d). All fragments are highly defective and are subdivided by nanoscale twin colonies forming a complicated hierarchical defect structure.

As stated above, during ECAP the strain is localized in the thin deformation zone formed by the intersecting channels. Depending on the ECAP die-set geometry, a certain heterogeneity in macroscopic strain distribution (and entailed difference in microstructure) along the height of the processed workpieces can be observed after a few first ECAP passes. However, this macroscopic heterogeneity disappears with increasing the number of passes, and in addition, it is not pronounced in case of a round cross section of the workpiece [13]. This highlights an additional benefit of the implementation of the multi-pass ECAP.

Figure 5 summarizes the results of the tensile tests of the TWIP steel subjected to ECAP for a different number of passes. Quantitative data of the yield stress $\left(\sigma_{0.2}\right)$, ultimate tensile strength $\left(\sigma_{\mathrm{UTS}}\right)$, and total elongation to failure $(\delta)$ are presented in Table 1.

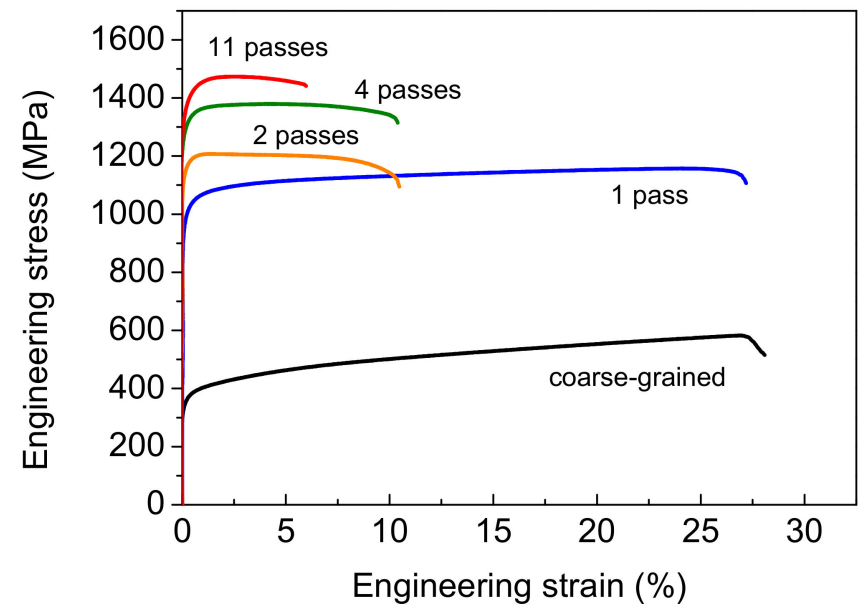

Figure 5. Engineering "stress-strain" curves of the TWIP steel before and after multi-pass ECAP.

Table 1. Mechanical properties of the TWIP steel in different structural states.

\begin{tabular}{cccc}
\hline State & $\sigma_{\mathbf{0 . 2}}, \mathbf{M P a}$ & $\sigma_{\mathrm{UTS}}, \mathbf{M P a}$ & $\delta, \%$ \\
\hline Coarse-grained & $342 \pm 16$ & $581 \pm 4$ & $32 \pm 5$ \\
1 ECAP pass & $987 \pm 4$ & $1151 \pm 5$ & $27 \pm 5$ \\
2 ECAP passes & $1152 \pm 5$ & $1202 \pm 5$ & $10 \pm 2$ \\
4 ECAP passes & $1302 \pm 5$ & $1372 \pm 5$ & $10 \pm 2$ \\
11 ECAP passes & $1363 \pm 5$ & $1465 \pm 6$ & $6 \pm 2$ \\
\hline
\end{tabular}

The presented data show that an increase in the number of ECAP passes from 1 to 11 leads to a gradual strengthening of the material accompanied by a loss in plasticity. Already 
after a single ECAP pass, the yield stress has increased more than twice compared to the initial state of the TWIP steel. With further ECAP passes, the strength gradually increases and reaches a maximum after 11 ECAP passes. This is in agreement with the microstructural data: the increase in strength can be explained by the refinement of structural elements and the evolution of a hierarchical defect structure in the ECAP processed steel.

Interestingly, the TWIP steel processed with one ECAP pass showed visible deformation banding on the sample surface after the tensile test (Figure 6), which was not observed for the higher number of ECAP passes. It indicates that the tensile tested specimen produced by one ECAP pass demonstrates macroscopic strain localization in the form of banding. This effect is visibly pronounced due formation of oriented deformation bands in very large initial grains achieved after a single ECAP pass. As follows from the analysis of Figures 1-4, this macroscopic banding is naturally suppressed with the next ECAP passes providing progressive microstructure refinement-such as formation of twin colonies inside the bands and fragmentation, leading to the abrupt loss in plasticity.

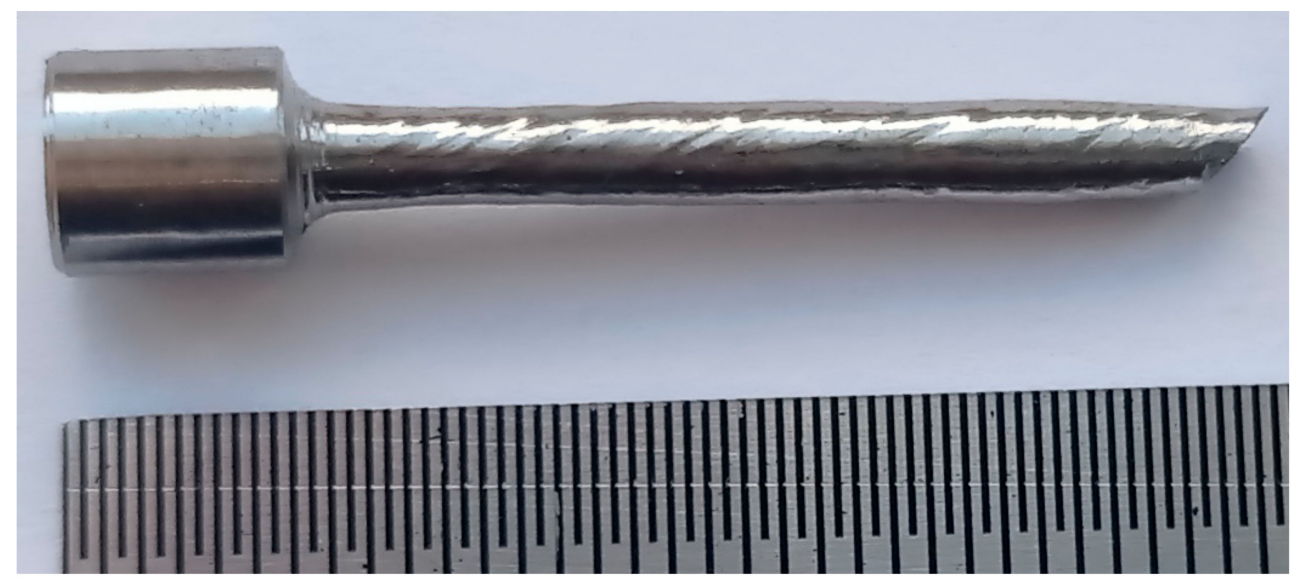

Figure 6. Deformation bands on the surface of the tensile specimen of the TWIP steel subjected to 1 ECAP pass in front of a ruler with $1 \mathrm{~mm}$ divisions.

3.2. Evolution of Microstructure and Mechanical Properties of the TWIP Steel Processed by Rolling and by a Combined ECAP + Rolling Treatment

In the present study, we propose an approach to additionally enhance the strength properties of TWIP steels based on the results obtained on the example of an austenitic stainless steel of 321 grade [14]. It was demonstrated that a combination of ECAP with conventional metallurgical techniques (such as rolling) had offered an additional way to increase mechanical performance compared to ECAP state. This effect was attributed to the substantial change of the strain path which activated additional slip systems, leading to a further refinement and a heterogeneous cell-granular microstructure with a high density of grain boundaries and a large fraction of twins [14].

In this subsection, we present the results related to the effect of warm rolling to the ECAP processed TWIP steel having the maximum strength (achieved after 11 ECAP passes) as well as to the coarse-grained steel for a comparative reason.

Figure 7 presents the microstructure of the TWIP steel after rolling at temperatures of $375{ }^{\circ} \mathrm{C}$ and $500{ }^{\circ} \mathrm{C}$. In agreement with the numerous literature data for warm rolling to similar thickness reduction $[15,16]$, the microstructure for both states becomes fragmented and is characterized by an increased defect density arranged in the form of dislocation assemblies and tangles, indicating dislocation slip as a dominant deformation mechanism. Retained grains are elongated: their width is about $500 \mathrm{~nm}$ and length-about a few microns. 


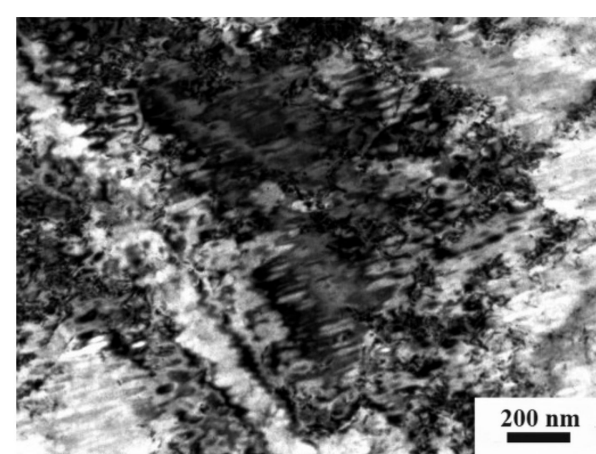

(a)

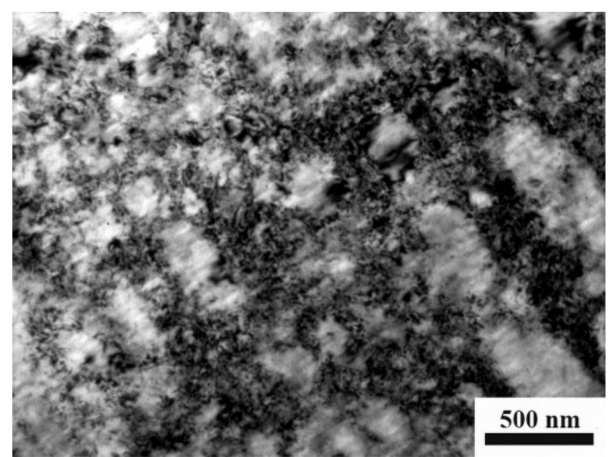

(b)

Figure 7. TEM images of the microstructure of the TWIP steel processed by warm rolling at temperatures of $375^{\circ} \mathrm{C}(\mathbf{a})$ and $500{ }^{\circ} \mathrm{C}(\mathbf{b})$.

The microstructure of the TWIP steel processed by the combined ECAP + rolling procedure appears considerably different (Figure 8). It is composed of submicron-sized fragments with their interiors filled by nanoscale twins in case of the steel processed by $\mathrm{ECAP}+$ rolling at $375^{\circ} \mathrm{C}$, but relatively free from dislocation substructures in case of the state produced by ECAP + rolling at $500{ }^{\circ} \mathrm{C}$. Images presented in Figure 8 also indicate a considerable heterogeneity in the produced microstructures.

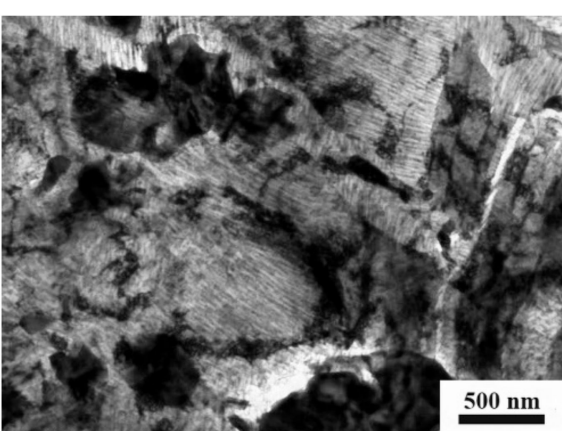

(a)

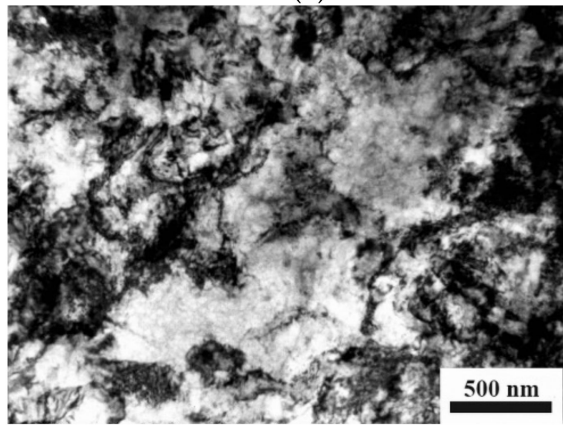

(c)

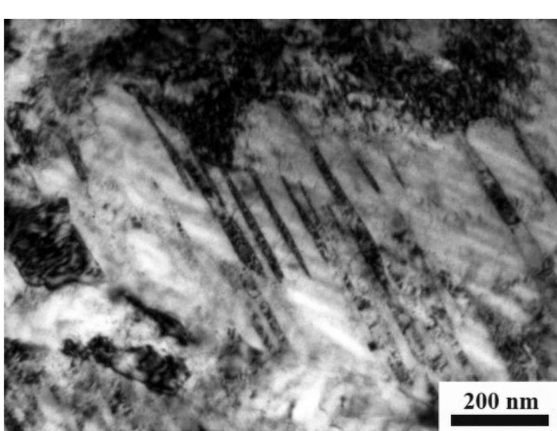

(b)

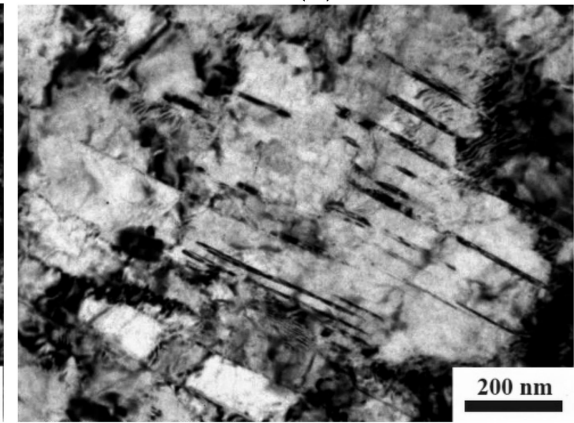

(d)

Figure 8. TEM microstructure of the TWIP steel processed by ECAP + rolling at temperatures of $375{ }^{\circ} \mathrm{C}(\mathbf{a}, \mathbf{b})$ and $500{ }^{\circ} \mathrm{C}(\mathbf{c}, \mathbf{d})$ taken at different magnifications.

The results of the tensile tests for the rolled and ECAP + rolled samples are presented in Figure 9 (deformation curves) and Table 2 (calculated mechanical parameters). Table 2 also contains the values of the calculated "yield strength-elongation to failure" product, and such an approach is often used in literature to characterize the "strength-plasticity" tradeoff [11]. Warm rolling of the coarse-grained TWIP steel at $375^{\circ} \mathrm{C}$ and $500{ }^{\circ} \mathrm{C}$ leads to the microstructural changes and corresponding modification of mechanical properties which are well consistent with the values reported in literature $[15,16]$. The tensile properties of the TWIP steel produced by rolling at $375{ }^{\circ} \mathrm{C}$ and $500{ }^{\circ} \mathrm{C}$ are within the inaccuracy of measurements found to be similar here. However, as we do not focus on the well- 
studied effect of plain warm rolling on the material's properties within this study, a typical deformation curve corresponding to these states is given in Figure 9 for comparison.

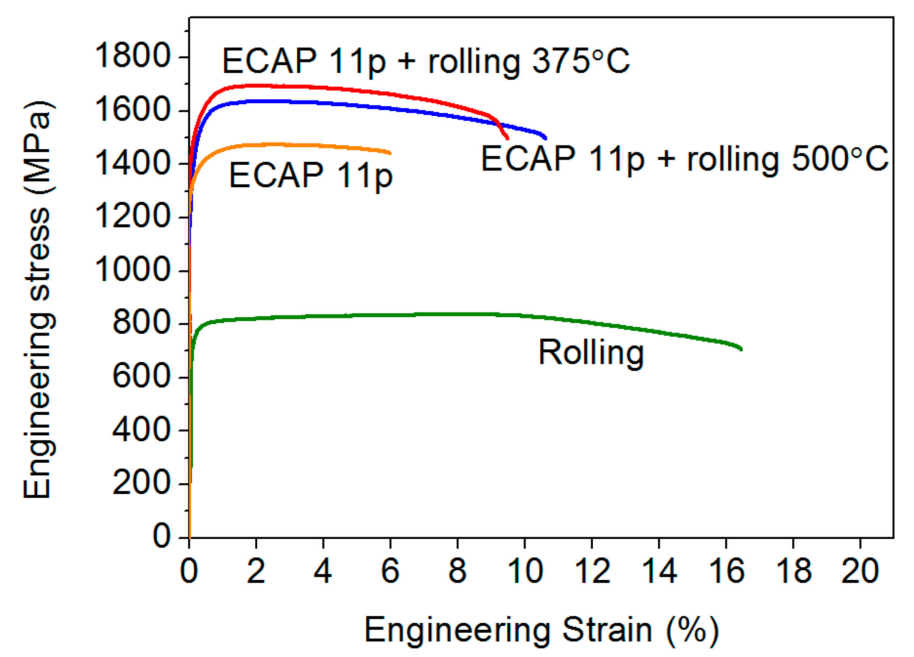

Figure 9. Engineering "stress-strain" curves for the TWIP steel processed by warm rolling, ECAP to 11 passes (denoted as ECAP 11p), and ECAP 11p + rolling at two temperatures. Note that the elongation to failure of the rolled and ECAP 11p + rolled samples cannot be directly compared to the elongation to failure of the ECAP 11p samples due to different designs of the tensile specimens.

Table 2. Mechanical properties of the TWIP steel subjected to rolling and ECAP to 11 passes (denoted as ECAP 11p) + rolling.

\begin{tabular}{ccccc}
\hline State & $\sigma_{\mathbf{0 . 2}}, \mathbf{M P a}$ & $\sigma_{\text {UTS }}, \mathbf{M P a}$ & $\delta, \%$ & Product (MPa \%) \\
\hline Rolling at $375{ }^{\circ} \mathrm{C}$ & $790 \pm 16$ & $848 \pm 17$ & $16 \pm 1$ & 12,640 \\
Rolling at $500^{\circ} \mathrm{C}$ & $789 \pm 18$ & $880 \pm 17$ & $12.5 \pm 1$ & 9863 \\
ECAP 11p + rolling at $375{ }^{\circ} \mathrm{C}$ & $1541 \pm 11$ & $1666 \pm 24$ & $8 \pm 1$ & 12,328 \\
ECAP 11p + rolling at $500{ }^{\circ} \mathrm{C}$ & $1475 \pm 6$ & $1630 \pm 7$ & $10 \pm 1$ & 14,750 \\
\hline
\end{tabular}

The data presented in Figure 9 and Table 2 testify that warm rolling is capable of additionally improving the mechanical performance of the heavily deformed TWIP steel. For both rolling temperatures, the achieved strength levels seem to be the highest ever reported for TWIP steels with a similar chemical composition processed by ECAP or rolling.

\subsection{Evolution of the Microhardness of the TWIP Steel in Different Structural States} after Annealing

The effect of annealing for $1 \mathrm{~h}$ on the microhardness of the produced states of the TWIP steel has been preliminary investigated (Figure 10). These data are of particular interest for two specific reasons: (i) it is important to define a temperature range where the level of achieved properties is reliably preserved, and (ii) earlier promising results on further strength improvements with the help of additional thermal treatments of heavily deformed states due to formation of recovered and partially recrystallized structures [17] and presumably by segregation phenomena [18]. 


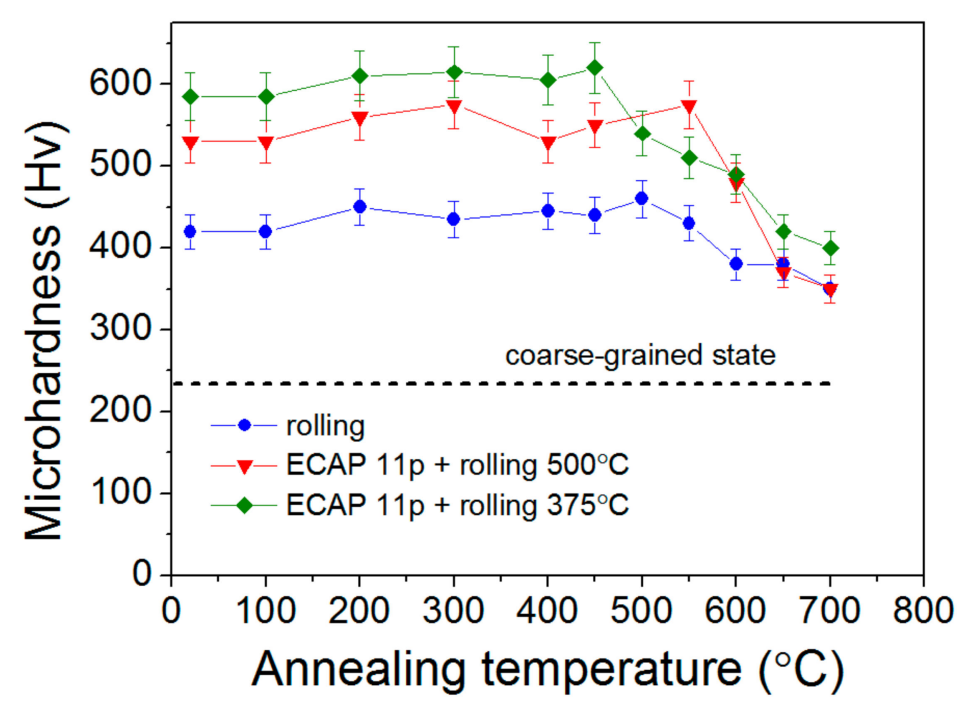

Figure 10. Microhardness of the TWIP steel in different structural states as a function of annealing temperature.

The data presented in Figure 10 indicate that there is a certain increase in microhardness with annealing temperature in the range of 200 to $450{ }^{\circ} \mathrm{C}$ with a notable decrease after reaching $500-550{ }^{\circ} \mathrm{C}$. After annealing at $700^{\circ} \mathrm{C}$, a significant drop in microhardness is observed for all states indicating the onset of recrystallization. However, the absolute hardness values are still higher than those of the fully recrystallized coarse-grained material (a dashed line on the plot). The state corresponding to ECAP + rolling at $500{ }^{\circ} \mathrm{C}$ demonstrates the best thermal stability, which is preserved up to temperatures of about $550{ }^{\circ} \mathrm{C}$. A comprehensive study of annealing-related effects is planned as a future work.

\section{Discussion}

The results of the microstructural evolution of the TWIP steel during progressive ECAP at $400{ }^{\circ} \mathrm{C}$ up to four passes are consistent with the data published in literature for processing at similar temperatures $[10,11]$. The microstructure of high-Mn TWIP steels evolves from highly twinned initial grains to a heterogeneous structure composed of deformation bands, heavily distorted by arrays of nanotwins and dislocation configurations. Deformation twins are observed at all deformation stages, but with increasing strain twin spacing and dimensions tend to decrease. ECAP for two times higher number of passes $(n=11)$ leads to exhausting of twinning ability. Further fragmentation occurs by interaction of deformation bands, resulting in the formation of newly created elongated subgrains/fragments densely inhabited with arrays of nanoscale twins. Such a microstructure would provide fast localization of internal stresses under loading, and this significantly affects further ECAP processing due to massive crack initiation followed by fracture of the workpieces. This puts a barrier on reaching a true ultrafine-grained state consisting of grains with mostly high angle grain boundaries, for instance, achievable by using HPT [5-7]. These observations are quite consistent with the results of the tensile tests. The strength gradually increases while elongation to failure shows the opposite trend. The maximal achieved strength seems to be one of the highest ever reported for the ECAP or rolling processed TWIP steel with a Mn concentration corresponding to the lower limit required for the manifestation of the TWIP effect.

Most of the studies aiming at achieving high yield stress in TWIP steels report values not exceeding 1000-1200 MPa [12]. In a few papers, even higher yield strength values were reported, for example, for Fe-23Mn-0.3C-1.5Al steel subjected to heavy cold rolling [19] yield stress reached $\sim 1400 \mathrm{MPa}$ with an ultimate tensile strength of $1580 \mathrm{MPa}$, accompanied with an abrupt decrease in elongation to failure (3.9\%). A similar combination of strength parameters was demonstrated in case of $\mathrm{Fe}-18 \mathrm{Mn}-0.3 / 0.6 \mathrm{C}$ steel, processed by cold rolling with intermediate recrystallization annealing [20]. Note that increasing Mn concentration 
in the coarse-grained state of TWIP steels leads to a decrease in the yield strength [16] and increase in the intrinsic stacking fault energy in the Mn concentration range from 16 at.\% to 33 at.\% [21]. Mn also reduces the diffusivity of C in Fe [21], and together with a higher content of $\mathrm{Mn}$ in solid solution, all these indirect effects could lead to differences in strain-induced microstructural modifications, for instance, by competition of dislocation multiplication with localization of plastic flow and twinning processes. Therefore, a comparison of the obtained results can only be applied to TWIP steels of the same chemical composition. Thus, the present study confirms a great potential of multi-pass ECAP to obtain a superior mechanical performance of the particular TWIP steel.

Note that the elongation to failure of the strongest states of the ECAP-processed TWIP steels seems to be notably smaller than those reported for the TWIP steels with similar strength, produced, for example, by rolling [20]. However, as standard tensile samples were intentionally used for the testing of ECAP-processed steel, we assume that the revealed trend for reduction in plasticity is relevant.

Warm rolling of the ECAP processed TWIP steel resulted in a considerable increase in strength compared to the ECAP state. $\sigma_{0.2}$ and $\sigma_{\mathrm{UTS}}$ reach $1547 \mathrm{MPa}$ and $1666 \mathrm{MPa}$, respectively, which are the highest strength values of TWIP steels of a similar composition processed by ECAP or rolling $[1,2,12,17]$ and even by accumulative roll bonding [22]. However, the strength levels achievable by high pressure torsion (2600 MPa) still remain unbeatable, emphasizing that the microstructure is not refined to a saturation state even after multi-pass ECAP.

Note that a direct comparison of the effects of additional warm rolling on elongation to failure of the ECAP TWIP steel is complicated since the tensile specimens for ECAP and rolled samples had different geometry. It is well known that using miniaturized samples overestimates the total elongation to failure for nanostructured materials as well as affects the reduction in area [23]. Therefore, the increase in this parameter of the ECAP + rolling specimens compared to the ECAP state (Figure 9) can be considered as appearing. However, the uniform elongation parts on the deformation curves are similar for ECAP and ECAP + rolling at $375{ }^{\circ} \mathrm{C}$ and somewhat larger for ECAP + rolling at $500{ }^{\circ} \mathrm{C}$. As the uniform elongation is not affected by the tensile specimen geometry [23], this indicates a slightly higher work hardening rate and ductility of the former state.

Due to the complexity of the produced microstructures having a hierarchical character, pointed out also in [22,24], the quantitative characterization of structural parameters and evaluation of their impact on properties is a rather sophisticated task and can be a subject of dubious interpretation. In addition, application of techniques such as electron backscatter diffraction is heavily obstructed by the high internal stresses provided by different defects of high density and nanoscaled dimensions. This dramatically lowers the detection and indexing rate of this technique. Future studies thus need to focus on techniques with higher lateral resolution, such as transmission Kikuchi diffraction, or precession electron diffraction to obtain reliable quantitative data of the nanoscaled deformation structures.

However, the qualitative changes between the states produced by ECAP and by ECAP + rolling captured by conventional TEM can be analyzed. Comparing Figures 4 and 8 shows that there is a clear transition from elongated banded structures to more equiaxed ones. As discussed in [14], this can be attributed not only to the introduced extra-strain, but also to the strain path change itself, which can activate additional slip (and twin) systems thus providing additional capability to digest plastic flow without fracture while further fragmenting the microstructure. Indeed, the change of the deformation technique can provide an additional opportunity for further hardening. First, the strain induced by rolling $(47 \%)$ is approximately twice less than that induced by a single ECAP pass, so the material can stand this additional deformation without fracture. Second, even though the shear plane is changed at every ECAP pass, by multiple ECAP we reach states where repeated strain mode leads to saturation of deformation activity in the activated slip systems and to formation of the particular deformation texture. A cardinal change in the deformation mode-both in stress tensor (rolling vs. shear) and in direction of 
loading-would activate the slip systems in grains/fragments, which become favorably oriented for the new loading conditions. The fragmented equiaxed structures produced by ECAP + rolling provide higher strength while preserving a similar level of plasticity. Higher rolling temperatures $\left(50{ }^{\circ} \mathrm{C}\right)$ lead to a decreasing intragranular defect density. In addition, the size of structural elements, such as subgrains and twin spacing, is somewhat larger for the ECAP + rolling at $500{ }^{\circ} \mathrm{C}$ samples compared to the ECAP + rolling at $375{ }^{\circ} \mathrm{C}$ samples. Correspondingly, these differences provide increasing in elongation to failure while maintaining slightly lower strength than after rolling at $375^{\circ} \mathrm{C}$. Still, the strength values of the TWIP steel produced by ECAP + rolling at $500{ }^{\circ} \mathrm{C}$ exceed those achieved by multi-pass ECAP. As a result, the "yield strength-elongation to failure" product is the highest among all studied cases given in Table 2.

Note that the TWIP steel produced by ECAP + rolling shows a certain increase in hardness after annealing at temperatures in the range of 200 to $400{ }^{\circ} \mathrm{C}$. This is consistent with a similar observation reported in [18], where it was attributed to segregation/clustering of solutes due to severe lattice distortions induced by SPD. This process can be diffusionenhanced at an elevated temperature where the higher density of clusters can provide pinning of interfaces and explain the fact that the TWIP steel after ECAP + rolling at $500{ }^{\circ} \mathrm{C}$ demonstrates also higher thermal stability as compared to the other investigated cases. The effect of the post-deformation heat treatment on the mechanical properties of the produced states requires a separate detailed study with the help of atomic-scale microstructural characterization techniques.

\section{Conclusions}

It can be concluded that a combination of ECAP with conventional metal-forming processes such as rolling can be considered as a promising approach to additionally improve the mechanical properties of bulk workpieces of TWIP steels having commercially attractive shapes. Rolling of multi-pass ECAP specimens at $375{ }^{\circ} \mathrm{C}$ allowed achieving the highest yield strength (1541 MPa) among all the investigated cases as well as those reported in literature for ECAP and rolling. The best combination of strength and elongation combined with better thermal stability is reached using multi-pass ECAP followed by rolling at $500{ }^{\circ} \mathrm{C}$. Such a combination could be beneficial to improve the crack resistance and impact toughness of this steel as well as formability demanded by industrial applications. Clarifying these issues together with investigations of the effects of annealing treatments are promising directions for further studies.

Author Contributions: Conceptualization, H.S.K., M.A., J.G.K., and N.E.; methodology, A.R., G.H.J., and M.A.; validation, M.A. and J.G.K.; formal analysis, C.S.L., O.R., and N.E.; investigation, M.A., A.K., and A.R.; resources, A.R.; data curation, M.A., A.K., and G.H.J.; writing-original draft preparation, N.E.; writing-review and editing, N.E., O.R., J.N.K., and C.S.L.; visualization, M.A. and J.N.K.; supervision, R.Z.V. and H.S.K.; project administration, C.S.L. and N.E.; funding acquisition, H.S.K. and R.Z.V. All authors have read and agreed to the published version of the manuscript.

Funding: This research was funded jointly by Russian Foundation for Basic Research and National Research Foundation of Korea through the satellite projects: RFBR No 19-53-51012 (NIF_a) and No 2019K2A9A1A06099931 funded by Ministry of Science and ICT and by NRF grant funded by the Korea government (MSIP) No 2021R1A2C3006662.

Institutional Review Board Statement: Not applicable.

Informed Consent Statement: Not applicable.

Data Availability Statement: Data is contained within the article.

Acknowledgments: Part of the experimental work was performed using facilities of the "Nanotech" Center for Collective Use (Ufa State Aviation Technical University).

Conflicts of Interest: The authors declare no conflict of interest. 


\section{References}

1. Grässel, O.; Krüger, L.; Frommeyer, G.; Meyer, L.W. High strength Fe-Mn-(Al, Si) TRIP/TWIP steels development-PropertiesApplication. Int. J. Plast. 2000, 16, 1391-1409. [CrossRef]

2. Bouaziz, O.; Allain, S.; Scott, C.P.; Cugy, P.; Barbier, D. High manganese austenitic twinning induced plasticity steels: A review of the microstructure properties relationships. Curr. Opin. Solid State Mater. Sci. 2011, 15, 141-168. [CrossRef]

3. Rahman, K.M.; Vorontsov, V.A.; Dye, D. The effect of grain size on the twin initiation stress in a TWIP steel. Acta Mater. 2015, 89, 247-257. [CrossRef]

4. Valiev, R. Nanostructuring of metals by severe plastic deformation for advanced properties. Nat. Mater. 2004, 3, 511-516. [CrossRef]

5. Matoso, M.; Figueiredo, R.; Kawasaki, M.; Santos, D.; Langdon, T. Processing a twinning-induced plasticity steel by high-pressure torsion. Scr. Mater. 2012, 67, 649-652. [CrossRef]

6. Abramova, M.M.; Enikeev, N.A.; Kim, J.G.; Valiev, R.Z.; Karavaeva, M.V.; Kim, H.S. Structural and phase transformation in a TWIP steel subjected to high pressure torsion. Mater. Lett. 2016, 166, 321-324. [CrossRef]

7. Kim, J.G.; Enikeev, N.A.; Seol, J.B.; Abramova, M.M.; Karavaeva, M.V.; Valiev, R.Z.; Park, C.G.; Kim, H.S. Superior strength and multiple strengthening mechanisms in nanocrystalline TWIP steel. Sci. Rep. 2018, 8, 11200. [CrossRef] [PubMed]

8. Valiev, R.Z.; Zhilyaev, A.P.; Langdon, T.G. Bulk Nanostructured Materials: Fundamentals and Applications; John Wiley \& Sons: Hoboken, NJ, USA, 2013; pp. 1-456.

9. Bagherpour, E.; Reihanian, M.; Ebrahimi, R. On the capability of severe plastic deformation of twining induced plasticity (TWIP) steel. Mater. Des. 2012, 36, 391-395. [CrossRef]

10. Timokhina, I.; Medvedev, A.; Lapovok, R. Severe plastic deformation of a TWIP steel. Mater. Sci. Eng. A 2014, 593, 163-169. [CrossRef]

11. Haase, C.; Kremer, O.; Hu, W.; Ingendahl, T.; Lapovok, R.; Molodov, D.A. Equal-channel angular pressing and annealing of a twinning-induced plasticity steel: Microstructure, texture, and mechanical properties. Acta Mater. 2016, 107, 239-253. [CrossRef]

12. Yang, G.; Kim, J.-K. An Overview of High Yield Strength Twinning-Induced Plasticity Steels. Metals 2021, 11, 124. [CrossRef]

13. Valiev, R.Z.; Langdon, T.G. Principles of equal-channel angular pressing as a processing tool for grain refinement. Progr. Mater. Sci. 2006, 51, 881-981. [CrossRef]

14. Karavaeva, M.V.; Abramova, M.M.; Enikeev, N.A.; Raab, G.I.; Valiev, R.Z. Superior strength of austenitic steel produced by combined processing, including equal-channel angular pressing and rolling. Metals 2016, 6, 310. [CrossRef]

15. Belyakov, A.; Kaibyshev, R.; Torganchuk, V. Microstructure and Mechanical Properties of $18 \%$ Mn TWIP/TRIP Steels Processed by Warm or Hot Rolling. Steel Res. Int. 2017, 88, 1600123. [CrossRef]

16. Haupt, M.; Müller, M.; Haase, C.; Sevsek, S.; Brasche, F.; Schwedt, A.; Hirt, G. The Influence of Warm Rolling on Microstructure and Deformation Behavior of High Manganese Steels. Metals 2019, 9, 797. [CrossRef]

17. Kusakin, P.S.; Kaibyshev, R.O. High-Mn twinning-induced plasticity steels: Microstructure and mechanical properties. Rev. Adv. Mater. Sci. 2016, 44, 326-360.

18. Kim, J.G.; Seol, J.B.; Bae, J.W.; Kim, H.S. On the mechanistic understanding of annealing-induced strength enhancement of ultrafine-grained high-Mn steel. Materialia 2020, 13, 100837. [CrossRef]

19. Kusakin, P.; Belyakov, A.; Haase, C.; Kaibyshev, R.; Molodov, D.A. Microstructure evolution and strengthening mechanisms of Fe-23Mn-0.3C-1.5Al TWIP steel during cold rolling. Mater. Sci. Eng. A 2014, 617, 52-60. [CrossRef]

20. Torganchuk, V.; Belyakov, A.; Kaibyshev, R. Improving Mechanical Properties of 18\%Mn TWIP Steels by Cold Rolling and Annealing. Metals 2019, 9, 776. [CrossRef]

21. De Cooman, B.C.; Estrin, Y.; Kim, S.K. Twinning-induced plasticity (TWIP) steels. Acta Mater. 2018, 142, 283-362. [CrossRef]

22. Etemad, A.; Dini, G.; Schwarz, S. Accumulative roll bonding (ARB)-processed high-manganese twinning induced plasticity (TWIP) steel with extraordinary strength and reasonable ductility. Mater. Sci. Eng. A 2019, 742, 27-32. [CrossRef]

23. Zhu, Y.T.; Wu, X.L. Ductility and plasticity of nanostructured metals: Differences and issues. Mater. Today Nano 2018, 2, 15-20. [CrossRef]

24. Li, Y.; Lu, Y.; Li, W.; Khedr, M.; Liu, H.; Jin, X. Hierarchical microstructure design of a bimodal grained twinning-induced plasticity steel with excellent cryogenic mechanical properties. Acta Mater. 2018, 158, 79-94. [CrossRef] 